To cite this paper

Kourkoutas, E., Hart, A. Kassis, W. \& Graaf, U. (2017). A Resilience-based Program to Promote Reflective and Inclusive Teaching Practices in Greece during Austerity. In Amzat, H. I. \& Valdez, N. (Eds.) Teacher Professional Knowledge and Development for Reflective and Inclusive Practices (pp. 168-178). New York, NY: Routledge

\title{
A Resilience-based Program to Promote Reflective and Inclusive Teaching Practices in Greece during Austerity
}

Elias Kourkoutas, Angie Hart, Wassilis Kassis \& Ulrike Graaf

University of Crete, University of Brighton, University of Zurich, University of Heidelberg

\begin{abstract}
In this paper we present the key epistemological assumptions and the theoretical background of a resilience-based program within Greek schools. The program aimed to help teachers develop self- and practice-based reflective skills, as well as reducing stress and confusion in their work with "difficult" or challenging students. Primary results of a qualitative evaluation showed significant improvement both in teachers' -awareness about their students' psychosocial and family problems and self- or practice-based reflective skills regarding inclusive issues.
\end{abstract}

\section{Introduction: Setting the Context of the Contemporary Educational and Epistemological Challenges}

Inclusive Education challenges the traditional special education approaches, which are based on a medical paradigm and a competitive and individualistic school culture, by advocating for a different conceptualization of SEN and educating students within the mainstream school context (Ainscow et al., 2006; Allen, 2007).

However, research shows that, despite the widespread acceptance of inclusive values, when students' challenging behaviours and social-emotional problems cannot be managed by teachers, this may lead to puzzling situations or inappropriate educational practices, trapping the educational staff in a cycle of negative or ineffective reactions with "problem" students (Kaufman \& Landrum, 2013; Kourkoutas \& Wolhuter, 2013). This reduces their professional competence and 
jeopardizes the teacher-student relationship, which is a critical factor in children's psychosocial and academic resilience (Beltman et al., 2011; Fleming, Mackrain \& LeBuffe, 2013). Such unresolved, contradictory or troubling situations undermine inclusive provision and teachers' sense of professional identity, self-competence and emotional well-being (Henricsson \& Rydell, 2004).

Most teachers also recognize that, despite their personal commitment to inclusive values and their willingness to positively respond to students, lack of knowledge and specialized guidance often lead to distressing situations or unsuccessful attempts to deal with challenges that arise (Cooper \& Jacobs, 2011; MacBeath et al., 2006; Kourkoutas et al., 2011).

Moreover, there is evidence that few general education classroom teachers are adequately supported to help and include students with serious social, emotional and behavioural problems, or are trained in effective methods and strategies for engaging with students in an efficient way (Simpson \& Mundschenk, 2012).

Overall, even where a positive school ethos encourages inclusive practice, many teachers are concerned about their individual capacity and the capacity of their schools to develop inclusive learning environments (Mansfield et al., 2016; MacBeath et al., 2006)

Many critics have addressed the political/ideological character of the inclusive paradigm, highlighting a lack of evidence-based and effective practical methods, which leaves many children at risk without special assistance or support (Anastassiou \& Kauffman, 2011).

Our research and school-based intervention agenda is guided by the concept of social-emotional and academic/professional resilience (social-relational, communication and self-expression skills, creativity, critical reflection, selfawareness, etc.) in students with social-emotional-behavioral and learning difficulties (SEBLD), their teachers and parents.

Within the wider frame of the social model of disability and the inclusive paradigm, the key assumption of our theoretical and research approach is the need to support teachers in their inclusive work, as teacher is the spearhead of inclusive practice. This is not to underestimate the important resilience work done by other professionals involved in the school community.

\section{Conceptualizing Resilience and Reflective Practice in Teachers within the wider Inclusive Education Framework}

A positive relationship between teacher and student is an important factor in inclusive education as it promotes learning and, more generally, supports the psychosocial development of the child (Cefai, 2008). As a result, a negative relationship can seriously affect the social and school adjustment and psychosocial development of the child, more so if there are also behavioural or emotional problems present (Kaufman \& Landrum, 2013).

Teachers have a central role to play in this. They are critical to securing an inclusive and supportive classroom dynamic that is beneficial for all vulnerable students (Cohen, 2013). 
Consequently, emphasis has recently been placed on exploring factors which prevent teachers from feeling overwhelmed by anxieties related to personal or professional inadequacies, as well as on developing strategies to combat inflexible, inappropriate, or negative/rejecting attitudes towards their "problem" students (Cooper \& Jacobs, 2011).

A literature review of resilience in education highlights a series of individual and contextual considerations which are significant in promoting or hindering teacher resilience and reflective skills (Beltman et al., 2011; Masten \& Obradovic, 2006).

Among the most significant individual risk factors are: negative self-beliefs and confidence, reluctance to seek help, lack of collaborative practice, conflict between personal beliefs and practices, distressing emotional responses to challenging situations, and inadequate coping strategies to alleviate stress or conflicting emotions (e.g. selection of sub-optimal coping strategies such as aggressive or over-dominant classroom management approaches) (Fantilli \& McDougal, 2009; Mansfield et al., 2016).

As for the most significant environmental risk factors, these include: unsupportive leadership and/or uncooperative colleagues, behaviour management (student disruptions and discipline), heavy workloads and poor working conditions, role ambiguity, lack of school structure, and lack of inclusive ethos (Beltman et al., 2011).

Resilient and reflective teachers have been described as having the capacity to thrive in difficult circumstances; they are skilled in behaviour management, able to empathize with problem students, reflect on their own practice, restrain negative emotions and focus on the positive they experience a sense of fulfilment and increased commitment to their school, profession and in helping vulnerable students (see Mansfield et al., 2016).

The philosophy of inclusive education, as has been defined by many researchers, is consistent with and very close to the philosophy and practice of resilience (Ainscow et al., 2006; Barbarasch \& Elias, 2009; Cohen, 2013; Doll, 2013).

In fact, resilience-based models, unlike medical ones, are not deficit-centred; rather they focus on exploring and strengthening the positive aspects and components of the child's and teacher's functioning, emphasizing at the same time, a system-based and contextual approach. They, therefore, include families and school systems and promote school-community cooperation (Aumann \& Hart, 2009; Hart, Blincow with Thomas 2007).

As for the concept of reflective practice and its link to inclusive or resilient processes, we have referred to the following functional conceptualization: the teacher's professional knowledge and understanding of the complex classroom and individual dynamics includes "ways to reflect, evaluate and use research-informed critical thinking to develop his or her own inclusive strategies and attitudes and to share good practice with others".

Reflection on actions and interactions allows teachers to continually improve their practice and even to develop practice-based theory and research-based practice 
regarding the inclusion of students with difficulties. However, promoting processes that allow teachers to cultivate their own reflective skills is not an easy task.

From our point of view, the capacity of teachers to reflect on their own practice and become "inclusive and effective teachers" is closely related to the development of their social-emotional competence. A novel approach to cultivating social-emotional competence and self-reflective skills among educators has been the introduction of mindfulness training for teachers (Roeser, Skinner, Beers, \& Jennigs, 2012). This type of training may contribute to the improvement of inclusive teaching and learning, and leadership in schools.

Factors implicated in the activation and development of reflective processes among both students and educators include: (a) a supportive environment ensuring a sense of meaning, protection, self-value and confidence; (b) the availability of a social or professional educational network; (c) the ability to perceive one's own personal value; and (d) the cultivation of socio-emotional competence (Kinman \& Grant, 2011; Urquhart, 2009).

Notwithstanding the complexity of those processes, our previous studies have shown that when teachers experience a supportive and guiding professional environment, they are able to develop essential reflective skills, becoming highly creative and inventive in terms of inclusive practices (Kourkoutas \& Giovazolias, 2015). Teachers need to work with experienced professionals who are able to provide them with the knowledge they lack regarding the intra- and interpersonal processes involved in students' academic and personal resilience (Kourkoutas \& Hart, 2014).

\section{The Greek Social-Educational Context}

As the rates of unemployment and family mental-health problems have raised dramatically, the percentage of children requiring specialized support and assistance within schools has steadily increased during the years of the social-economic crisis and now varies between 25\% and 30\% (Anagnostopoulos \& Soumaki, 2012). In fact, many parents declare that they feel unable to deal with the social-economic challenges and cannot cope with their children's and adolescents' developmental challenges and difficulties (Anagnostopoulos \& Soumaki, 2012;).

According to teachers' statements, the austerity measures imposed on the Greek educational system have significantly reduced school resources, increasing their difficulties in including challenging students. Furthermore, they strongly emphasize the huge gap between theory and practice in training programs and the rising complexity of pupils' SEBLD, as well as the higher demands placed upon them (Antoniou, Plychroni, \& Kotroni, 2009).

Although quite resistant in the past to curricula transformations proposed by an inclusive paradigm (Zoniou-Sideri \& Vlachou, 2006), teachers in Greece have progressively adjusted their work to fit inclusive models. However, research shows that in many schools (Greek schools included) good intentions, combined with inadequate staff training has proven to be a recipe for failure, often contributing to a rising tide of social, emotional and behavioural difficulties which, in turn, result in the educational staff becoming "emotionally exhausted and feeling they have reached a professional impasse" (Cooper \& Jacobs, 2011; MacBeath et al. 2006). 
Greek teachers definitely require adequate training and school-based specialized support that is meaningful for them and helpful for developing caring attitudes and specific educational/teaching strategies with their "problem" students, which are at the core of the inclusive project (Simpson \& Mundschek, 2012).

Greek teachers need to reflect on their own practice and strategies and widen their perception and understanding of their "difficult" students' internal and contextual dynamics; they should be helped in meaningful ways to overcome their internal or external barriers, and take advantage of their personal and contextual resources (Kourkoutas \& Giovazolias, 2015). This kind of specialized assistance should take the form of a supporting and reframing structure (in the sense of a scaffold) which helps teachers engage in mindful ways with their "problem" students.

Overall, the ultimate goal is to help teachers reflect on and transform their traditional special educational practices and develop social-emotional learning methods that are child-centred and focus on the promotion of academic and psychosocial resilience for students with complex needs/difficulties.

\section{Rationale and Theoretical Background of our Resilience-Based Inclusive Implemented Model}

In recent years, we have been elaborating and implementing a number of research-led and teacher-centred intervention programs within Greek schools with the aim of supporting teachers to become more resilient, creative and reflective in terms of teaching and educating students with complexities. Furthermore, through these programs we are seeking to challenge teachers' stereotyped ideas and medicalizing conceptions of childhood disorders/disabilities (e.g. that ADHD should mainly be treated psychiatrically), usually related to less effective strategies. Overall, the ultimate goal is to help teachers reflect on and transform their traditional special educational practices and develop social-emotional learning methods that are childcentred and focus on the promotion of academic and psychosocial resilience for students with complex needs/difficulties.

Our aims have been to strengthen the school's role in promoting students' social-emotional resilience and inclusion involves supporting teachers to overcome their personal, professional and contextual barriers, including any negative feelings (such as anger),and feel confident to extend their own areas of practice in more inclusive ways.

It is worth noticing that in the case of childhood adversity, a positive relationship with a reliable adult figure is one of the most crucial factors in the development of strengths, achievement of resilience outcomes and avoidance of psychopathology (Luthar, 2006). Consequently, caring classroom relationships, meaningful engagement, shared values and a sense of belonging have consistently been shown to be related to positive academic and social outcomes among pupils, including those considered at risk of school failure and psychosocial difficulties (Cefai, 2008).

Findings from intervention programs focusing on enhancing teachers' emotional intelligence and caring attitudes have shown an increase in introspection, emotional awareness, emotional regulation and understanding of students' problems and difficulties (Hen \& Sharabi-Nov, 2013). A teacher's emotional intelligence and 
reflective skills are considered essential components of good inclusive practice with "problem" pupils, enhancing those students' academic and emotional resilience and transforming classroom and school culture (Cohen, 2013).

A key idea of our project was to facilitate the inclusion of "problem", at risk, and vulnerable students by promoting critical reflective processes and collaborative practices among teachers who encounter several difficulties in working with those students. To achieve such a goal, we felt it was crucial to create a "space" for professional exchange between members of the educational staff coming from different school backgrounds, under the guidance and supporting supervision of educational psychologists and academics/researchers who work within an inclusive and partnership-based reflective perspective.

Creating an opportunity for teachers articulate in a structured narrative their professional difficulties and impasses - in an environment where their problems, convictions, perceptions, and most importantly their feelings are listened to empathetically and understood - is the first significant step in developing an open, collaborative relationship that helps generate self-awareness and reflection on their own practice (Hanko, 2001; Kourkoutas, 2012).

In fact, it has been suggested that effective inclusive interventions should involve shared ownership, collaborative problem solving, co-construction of learning spaces, and emotional and professional experience exchange. Such a dynamic of interaction would enable school counsellors and educational staff to foster teachers' skills for introspection and insightful, empathetic, active responses to "challenging" students (Hanko, 2001).

\section{Key findings from a Community of Reflective Practice Program in Greek schools}

Our idea, as part of Imagine, a wider UK Research Council funded project developing resilience-based approaches through communities of practice, was to create a community of teachers and a space to share experience, learning and reflective practice to support them in their work with children and families with difficulties (http://www.boingboing.org.uk/index.php/research/our-research/14-staticcontent/our-research/130-imagine-project). We hoped that this would be spread within school units and educational communities and would change the way teachers perceive and deal with their students' difficulties.

Given the dearth of human resources in Greek schools, and in order to respond to the urgent need of teachers to be supported and guided for the promotion of the inclusion of "difficult" or vulnerable students, for the last three years we have been implementing a counselling intervention program in Cretan schools. More specifically, the intervention program has taken the form of a "Community of Reflective Practice" (CoRP) involving a large number of teachers and school professionals working with academics in an inclusive reflective perspective.

The program had an experimental and experience-based character and was significantly differentiated from classical school-based psychological interventions. More than 85 teachers, and 22 primary and secondary school units, have been involved in this program during the last three years, which has included 16-18 groupmeetings each year (20-30 persons, for 3.5 hours).

The Resilience Framework (Aumann \& Hart, 2009; Hart, Blincow and Thomas 2007), a guiding tool for professionals and teachers, was also integrated in 
our conceptual and procedural model of a CoRP, as a basic practical reference for teachers.

As for the group procedure, teachers were encouraged to talk freely about their problems and difficulties, and express ideas on how to proceed or deal with a series of critical school issues, including educating "difficult" students, dealing with those students' parents and families, classroom management and climate, relationships and professional engagement/cooperation with colleagues, alternative and inclusive teaching methods, practical issues related to inclusive ethos, and so on.

Teachers usually reported the case of a student who was difficult to teach and to include or a critical situation and the group was invited to reflect on the situation and exchange ideas, primarily on (a) the quality of the (social, family and school) dynamics of the cases, and (b) new perspectives to resolve/rebalance the situation in a meaningful way for the child and teacher.

Moreover, teachers were encouraged to reflect on their attitudes and the strategies they were using with their student. They were invited (a) to think why these strategies failed to help the specific student, (b) to understand the underlying psychological dynamics of the case, by developing a holistic and insightful understanding of the current situation (seeing the child within his family or social context, understanding the impact of family or classroom dynamics and the teacher's own attitude towards the student's behaviour) and (c) adopt a resilient thinking position (understanding the inner potential of the student).

After presenting the critical situation /difficult case, teachers were divided into small groups (5-6 groups of 6-7 persons). These groups were invited to first reflect on the case dynamics: the family and school context; the classroom reality and teacher attitude or practice; the student's individual skills, strengths, needs, and difficulties; the quality of his or her relationships with peers, adults, or parents; any relevant learning limitations, and so on. They were asked to then suggest strategies that would help the child function better in the classroom and to operate at a higher socialemotional and learning level.

At the beginning of each meeting, teachers who had previously presented a case about a difficult student were invited to relate how their work with this child had advanced as a result: what kind of progress had been achieved, whether they had encountered any barriers in their efforts to enhance their student's social-emotional wellbeing and learning abilities, whether there had been any reduction in the child's challenging or problematic behaviour and attitudes. This aspect of group work proved critical in promoting each participant's reflective thinking, as these real life situations made it possible to experiment with alternative ideas techniques, and test the efficacy of teachers methods.

In most cases, teachers reported significant improvement in their way of dealing with their students' problems and difficulties. In many cases of oppositional and disruptive behavioural problems, the use of innovative individualized educational methods had led to an improvement in the relationship with the child. The child's improvement was usually evaluated across multiple spheres and areas of activity. The quality of the child's inclusion was defined in terms of his/her social-emotional improvement and participation/engagement both in and out of the classroom. However, more research on the long-term impacts of such programs on "problem" children's inclusion and ability to function in school is needed.

One key axiom of the philosophy of this program was that teachers are wellpositioned to understand how to proceed with each child's case and to come up with new ways to respond. At the outset, participating teachers' main focus was to find out 
about strategies which could be used to deal with each "difficult" case, as they were encountering serious difficulties with traditional educational methods. However, rather than giving readymade solutions or simple expert advice, the group leaders promoted a collective reflective thinking process. The resultant "active learning" arising from this reflective process was the result of collective contribution and coconstruction of solutions.

Given that the way a child functions is largely regulated and influenced by significant others (parents, teachers and peers), we have opted for a transactional and systemic understanding of each student's difficulties and problematic behaviour (e.g. the behaviour of stealing was considered within the context of the child's family and school life, as well his personal needs, aspirations and difficulties). A considerable part of the discussion time was devoted to gaining thorough and meaningful insight into the underlying and contextual dynamics of the child's behaviour, seeking to understand his/her attitude or position within classroom, and relationship with learning and schooling more generally.

The following issues were discussed during the meetings: provocative or oppositional behaviour, antisocial and aggressive behaviour; bullying; stealing; vulnerable or socially withdrawn children coming from very difficult or extremely poor or dysfunctional family backgrounds; developmental disorders (autism); dealing with difficult parents.

Teachers who have participated in this program declared significant improvement in a series of areas, such as professional development and reflective practice (according to the $75.7 \%$ of our teacher sample). The following comments from 6 teachers' written reports are indicative: "the group work was really beneficial and enriching for my practice; it allowed participants to get different insights and think from different points of view; all teachers should participate in similar groups in order to discuss and express their concerns and their anxieties and search for solutions to their questions; the most useful thing in this group experience was that I got an awareness of new practices and management of challenging situations; I felt that it was very productive the fact that the group had always to propose various alternative psycho-pedagogical practices and activities in the classroom; the collective work and exchange opened up my minds in new ideas".

After the initial sessions, it was noticed that teachers started to become more critical and reflective, with respect to traditional school-practices, and more creative in suggesting broader and innovative strategies to deal with their students' problems. In addition, they also gradually started to explore and understand the child intrapersonal needs and difficulties and his/her family dynamics with the aim of involving parents in their work and exploiting their knowledge and skills. Regarding this issue, the CoRP team observed clear progress in terms of how teachers began to integrate the "contextual factor", as well as the social dimension of the children's problems, in their work. According to their own reports, they became less critical towards the parents of children considered "problematic", more tolerant and sensitized towards child's limitations and problematic behavior, and more able to "contain" their own anxieties and to approach the child positively or collaborate with parents. They claim that the CoRP work allowed them to become more cooperative and less critical with their colleagues, less self-blaming, and that they gained a more thorough insight into the students', families', and school's impasses, or strengths and limitations. The building of a trusting and supporting "holding" environment was a critical practical aspect of this program, as has been outlined by teachers in the evaluation process. 


\section{Conclusions}

The spaces of sharing and collaborative learning in a CoRP can help teachers open up to new ideas, and become self-reflective or critical towards traditional or ineffective Special Education practices. Such a group can have a very positive effect on the way teachers operate, especially when they are overwhelmed by intense negative emotions. School professionals working to create such spaces of learning and experience exchange, through the formation of CoRPs, can provide teachers with meaningful explanations in order to help them regain control and awareness of the complex processes activated when dealing with difficult students and their parents.

In fact, teachers need "personal spaces" and "spaces of learning and sharing" so that they can reflect on their own needs and strengths and consider ways to interact positively with "problem" students (Hanko, 2001). These "spaces to think and share" allow teachers to reflect more productively - and in a collective, collaborative way on how they work with "problem" students; such environments can help teachers to change their appraisal of difficult or distressing situations, reframing them as a professional challenge rather than a personal threat. CoRPs, in the way we have used them can fulfil the important role of opening new horizons in teacher practice (reflective function) and their perceptions of "difficult" students.

There is an urgent need to develop Greek teachers' capacity to work with other agents/professionals towards removing the structural and cultural barriers hindering "difficult" students' learning and participation. It will be necessary to challenge established views of teaching as an isolated teacher-classroom activity and to consider expanding our understanding of teacher competence and training to include teachers' relational agency and ability to work purposefully with other professionals, as well as developing teachers' awareness of the resources they can bring to bear in supporting a child with difficulties (Pantic \& Florian, 2015).

Educational psychologists, who work from an inclusive and partnership perspective, challenging the medical based models, can significantly contribute to the success of these projects (Kourkoutas \& Giovazolias, 2015). However, they should avoid positioning themselves as the omnipotent specialist or developing an antagonistic relationship with educational staff.

Overall, a safe space where teachers can reflect on inclusive issues, in combination with the necessary professional guidance, must be provided to help them find meaningful ways to respond to challenging students. Such spaces will allow teachers the opportunity to reflect on their own practice and create their own narratives and new systems of meaning about children's lives, and indeed about themselves; this would allow them to become more creative, receptive and welcoming. Hence, CoRP approaches such as the one we have described here, can enable teachers to become more resilient and inclusive to the benefit of students at risk, students' families and indeed teachers themselves.

\section{References}

Ainscow, M., Booth, T., \& Dyson, A. (2006). Improving schools, developing inclusion. London: Routledge.

Allen, J. B. (2007). Creating Welcoming Schools. New York: Teachers College Press. 
Anagnostopoulos, D. K., \& Soumaki, E. (2012). The impact of socio-economic crisis on mental health of children and adolescents. Psychiatriki, 23(1), 13-16.

Anastassiou, D. \& Kauffman, J. (2011). A Social Constructionist Approach to Disability: Implications for Special Education, Exceptional Children, 77, 3, 367384

Antoniou, A.-S., Polychroni, F., \& Kotroni, C. (2009). Working with students with special educational needs in Greece: Teachers' stressors and coping strategies. International Journal of Special Education, 24(1), 100-111.

Aumann, K. \& Hart, A. (2009). Helping children with complex needs bounce back: Resilient Therapy for parents and professionals. London: Jessica Kingsley.

Beltman, S., Mansfield, C., \& Price, A. (2011). Thriving not just surviving: A review of research on teacher resilience. Educational Research Review, 6(3), 185-207.

Brehm, K. \& Doll, B. (2009). Building resilience in schools. A focus on populationbased prevention. In R. W., Christner and R. B. Mennuti (Eds), School-based mental health a practitioner's guide to comparative practices (pp. 55-86). New York: Routledge.

Cefai, C. (2008). Promoting Resilience in the Classroom. London: J. Kingsley

Cohen, J. (2013). Creating positive school climate: A foundation for Resilience. In S. Goldstein \& R. B. Brooks (Eds.), Handbook of Resilience in Children (pp. 411422). New York: Springer

Cooper, P. \& Jacobs, B. (2011). From Inclusion to Engagement: Helping Students Engage with Schooling through Policy and Practice. Oxford: John Wiley.

Doll, B. (2013). Enhancing Resilience in classrooms. In S. Goldstein \& R. B. Brooks (Eds.), Handbook of Resilience in Children (pp. 399-410). New York: Springer

Fantilli, R.D., \& McDougall, D. E. (2009) A study of novice teacher: challenges and supports in the first years. Teaching and Teacher Education, 25, 814-825.

Fleming, J. L., Mackrain, M., \& LeBuffe, P. A. (2013). Caring for the caregiver: Promoting the resilience of teachers. In S. Goldstein \& R. B. Brooks (Eds.), Handbook of resilience in children ( $2^{\text {nd }}$ ed., pp. 387-397). New York, NY: Springer

Hanko, G. (2001). Difficult-to-teach children: Consultative staff support as an aspect of inclusive education: Sharing expertise across national and cultural boundaries. In J. Visser, H. Daniels, and T. Cole (Eds.), Emotional and behavioural difficulties in mainstream schools (pp.47-62). Oxford: Elsevier Sciences.

Hart, A., Blincow D., with Thomas H. 2007 Resilient Therapy: Working with families and children. London: Routledge.

Hart, A., Davies, C., Aumann, K., Wenger, E., Aranda, K., Heaver, B., \& Wolff, D. (2013). Mobilising knowledge in community-university partnerships: What does a community of practice approach contribute?' Contemporary Social Science: Special Issue. 8 (3), 278-291.

Henricsson, L., \& Rydell, AM (2004). Elementary school children with behavior problems: Teacher-child relations and self-perception. Merrill-Palmer Quarterly, 50, 111-138.

Kauffman, J. M. \& Landrum, T. J. (2013). Characteristics of emotional and behavioral disorders of children and youth. Boston: Pearson/Merrill

Kinman, G. \& Grant, L. (2011) Predicting stress resilience in trainee social workers: the role of emotional competencies. British Journal of Social Work, 41, 2, 261-275

Kourkoutas, E. (2012). Behavioral disorders in children: Ecosystemic psychodynamic interventions within family and school context. New York: Nova Science.

Kourkoutas, E. \& Hart, A., (2014). Suggesting a resilient and systemic oriented psychodynamic model to include students with behavioural problems: Theoretical 
issues and practical challenges. Journal of Clinical Psychology, 2, 147-168, doi:10.14645/RPC.2014.2.492

Kourkoutas, E. \& Raul Xavier, M. (2010). Counseling children at risk in a resilient contextual perspective: A paradigmatic shift of school psychologists' role in inclusive education. Social and Behavioral Science, 5, 1210-1219.

Kourkoutas, E. \& Wolhuter, C. C. (2013). Handling learner discipline problems: A psycho-social whole school approach, KOERS Journal for Christians Scholarships, 78, 3, 1-8, doi.org/10.4102/koers.v78i3.550

Kourkoutas, E., Georgiadi, M. \& Xatzaki, M. (2011). Teachers' perceptions of pupils' social dysfunctions: A combined qualitative and quantitative approach, Social and Behavioral Science, 15, 3870-3880

Luthar, S. S. (2006). Resilience in development: a synthesis of research across five decades. In D. Cicchetti \& D.J. Cohen (Eds.), Developmental Psychopathology: Risk, Disorder, and Adaptation: Vol 3 ( $2^{\text {nd }}$ Ed). New York: J. Wiley.

MacBeath, J., Galton, M., Steward, S., MacBeath, A., \& Page, C. (2006). The costs of inclusion: A study of inclusion policy and practice in English primary, secondary and special schools. Cambridge, UK: Faculty of Education, University of Cambridge.

Mansfield, C. F., Beltman, S., Broadley, T., \& Weatherby-Fell, N. (2016). Building resilience in teacher education: An evidenced informed framework, Teaching and Teacher Education, 54, 77-87

Masten, A. S. \& Obradovic, J. (2006). Competence and Resilience in Development, Annals: New York Academy of Sciences, 1094, 13-27

Rohner, R. (2010). Perceived Teacher Acceptance, Parental Acceptance, and the Adjustment, and Behavior of School-Going Youths Internationally. Cross-Cultural Research, 44, 3, 211-221.

Simpson, R. L., \& Mundschenk, N. A. (2012). Inclusion and Students with Emotional and Behavioral Disorders. In J. P. Bakken, F. E. Obiakor \& A.F. Rotatori (Eds.) Behavioral disorders: Practice concerns and students with EBD (pp. 1-22). Bingley, UK: Emerald Group

Urquhart, I. (2009). The psychology of inclusion: the emotional dimension. In P. Hick, R. Kershner, \& P. Farrell, (Eds.), Psychology for Inclusive Education: New directions in theory and practice (pp. 66-77). Abingdon: Routledge.

Zoniou-Sideri, A., \& Vlachou, A. (2006). Greek teachers' belief systems about disability and inclusive education. International Journal of Inclusive Education, 10(4-5), 379-394. 